\title{
Reacciones de los teólogos latinoamericanos a propósito de la Instrucción
}

\author{
LEONARDO BOFF \\ PABLO RICHARD \\ RONALDO MUÑOZ \\ JON SOBRINO \\ JULIO DE SANTA ANA
}




\section{Leonardo Boff}

El documento romano sobre la teología de la liberación suscita una cuestión fundamental y decisiva para una correcta comprensión del significado de la teología de la liberación. ¿La liberación de la cual se habla, es un tema térico candente para la coyuntura de miseria del Tercer Mundo, junto con otros temas pertinentes, $\mathrm{co}$ mo el trabajo, la sexualidad, la explosión demográfica, $O$ es antes que nada un proceso histórico, un fenómeno social apuntando al conjunto social e histórico de los oprimidos, concientizados y organizados en procura de vida de pan de trabajo de participación de dignidad, en una palabra, de una liberación integral? Según el sentido que demos a la liberación, si es como tema o si es como acción que libe. ra la libertad cautiva (por eso, liberación), cambia profundamente la comprensión de la Instrucción romana. En este punto se diferencian las perspectivas, aquella centroeuropea y aquella tipicamente tercermundista y latinoamericana.

La lectura centroeuropea de la liberación parte del terna en si. Liberación es un concepto fundamental de la teología bíblica y de la tradición emancipadora de la cultura moderna. Al abordarlo teológicamente, el teólogo investiga las Escrituras, la tradición, el magisterio y las opiniones recientes de los teólogos. Reconstruye, en forma sistemática, la idea de liberación y fundamenta, críticamente el tema. A continuación, extrae consecuencias para la vida concreta de los fieles en términos de orientaciones y direcciones posibles para prăcticas futuras $y$ viables.

La perspectiva latinoamericana y tercermundista parte de otro polo. Verifica el hecho de las prácticas de los oprimidos, cuáles son sus avances, quiénes son sus aliados; se pregunta cuál es la participación de los cristianos, de sectores de las Iglesias y de las comunidades eclesiales de base en este proceso mayor de libera. ción. A continuación se interroga, ¿qué relevancia tiene este camino y esta präctica para la realización del proyecto de Dios? ¿En qué medida este proceso realiza de manera incipiente e histórica el reino de Dios que es de justicia, de fraternidad y de paz? ¿Cómo se relaciona esta libera- 
ción concreta con la salvación de Jesús Cristo, ya que él, cuando estuvo entre nosotros, hizo seguramente una opción por los pobres, curó enfermos y liberó oprimidos? Por último, critica a la luz de la fe la presencia de los cristianos y las prácticas de los demás hombres y define acciones concretas en el sentido de reforzar la lucha por la liberación. A partir de este proce. so, desde adentro del compromiso, se procura realizar la reflexión de la fe (teología): ¿Qué imagen de Dios emerge entonces? ¿Qué figura de Cristo se dibuja para el militante cristiano? ¿Qué aspectos asumen el pecado y la gracia? ¿Qué señales confieren concreción a la esperanza cristiana? ¿Cómo debe ser la Iglesia para poder desempeñar su misión liberadora, a partir de su identidad religiosa irrenunciable?

La teología de la liberación nace del esfuerzo por responder a estas cuestiones planteadas por la práctica de liberación. El objeto de la reflexión no es sólo el tema biblico y tradi. cional, sino principalmente la realidad de la liberación de los oprimidos. Por el hecho de que este proceso concreto está vinculado a Dios, el cristiano se da cuenta de que la liberación es una realidad abierta hacia adelante y hacia arriba; hacia adelante en el sentido de no cerrarse sobre las conquistas alcanzadas, sino de buscar permanentemente formas más amplias de ejercicio de participación y de libertad; hacia arriba, en el sentido de elevarse hasta Dios, fuente de toda búsqueda de libertad, que confiere un carácter integral y pleno a la liberación, pues ella incluye y exige el perdón, la reconciliación y la resurrec. ción de los muertos, principalmente de los caidos y los martirizados por causa de la justicia.
Esta perspectiva constituye la originalidad de la teología de la liberación a diferencia de otras teologías sobre la liberación. La cuestión bắsica es la referencia a la práctica. Para escribir sobre el tema de la liberación sólo es preciso una sensibilidad mínima para captar su relevancia (de lo contrario no existe interés en abordarlo), se necesitan fuentes teológicas abundantes (exégesis, historia, documentación del magisterio sobre el tema, los textos de los teólogos que escribieron sobre el asunto), asi como capacidad de sistematización creadora y crítica. Esta tarea puede realizarse en la sala de estudio, dentro de las comodidades necesarias para toda investigación seria, fuera de la práctica real de liberación. A lo sumo es una práctica teórica.

Elaborar una teologĩa de la liberación a partir de la práctica de libera. ción presupone una inserción orgánica en un movimiento concreto, en una comunidad de base, en un centro de defensa de los derechos humanos, en un sindicato. Esta inmersión en el mundo de los pobres y de los oprimidos confiere al discurso teológico pathos, mordacidad a veces, iracundia sagrada y sentido de practicidad. Existe un interés objetivo por la eficacacia, porque lo que cuenta al final no es tanto la reflexión teológica, sino la liberación concreta de los pobres. Es esta liberación-acto y no tanto la liberación-pensamiento la que anticipa el reino y agrada a Dios. La opresión es más para ser superada que para ser pensada.

¿Cómo se sitúa la "Instrueción sobre algunos aspectos de la Teología de la Liberación" suscrita por el Cardenal J. Ratzinger y el Arzobispo A. Bovone? Se sitúa claramente dentro 
de la perspectiva centroeuropea de reflexión sobre el terna de la libera. ción. El texto no parte de la narración de las luchas de los oprimidos, de sus organizaciones y de la presencia de los cristianos dentro del proceso. Estos aspectos están totalmente ausentes. Parte de la "verdad esencial" de la liberación, como se dice inmediatamente en la "Introducción." Aborda el tema en el Antiguo y en el Nuevo Testamento, en el magisterio y en los documentos del episcopado latinoamericano. De alli deriva consecuencias para la práctica futura que aún no están previstas. La estrategia metodoIógica está definida claramente: "Discernir con claridad lo que es fundamental y lo que forma parte de las consecuencias es la condición indispensable para una reflexión teológica sobre la liberación" ("Introducción). Este enfoque metodológico inicial determina todo el desarrollo del tema. Es una Konsequenztheologle, como diría el mayor té́logo de este siglo, Karl Rahner, recién fallecido, una teología de las consecuencias de principios y de doctrinas.

No queremos desmerecer este procedimiento. Simplemente constatamos, inicialmente, la diferencia entre esta forma de pensar y la forma de pensar latinoamericana. No es una diferencia sin consecuencias.

La primera consecuencia de esta diferencia de enfoque radica en el hecho de que los teólogos latinoamericanos difícilmente se reconocerán en el texto presentado por las autoridades doctrinarias de Roma. En otro estilo, otro tipo de preocupaciones, otro acento.

La segunda consecuencia radica en el hecho de que la mayoría de las críticas de reduccionismo que se ha- cen a la teología de la liberación (o mejor, las teologías de la liberación, como prefiere el texto) no afectan en verdad a este tipo de teología. Los teólogos no están en absoluto negan. do la divinidad de Cristo, ni el valor redentor de su muerte, ni la misa como forma de actualización del sacrificio del Señor y de su presencia eucarística. En realidad, a partir de la práctica, colocan otros acentos. Parten de la fe compartida del pueblo de que Jesús es Dios, de que la misa posee un valor salvífico, etc. Pero enfatizan las dimensiones sociales y los desdoblamientos políticos presentes en estas realidades. Finalmente, Jesús fue condenado a muerte en un tribunal bajo Poncio Pilatos, celebró la última cena en un contexto de amenaza de muerte por parte de los poderes religiosos e ideológicos de la época, vivió cierto tipo de relaciones con los pobres, definió una posición altamente crítica frente a la riqueza y al poder dominación. Nuestros maestros medievales nos enseñaban: abstractio non est negatio, abstraer no significa negar. Tenemos que ver con los énfasis reclamados por la realidad vivida y sufrida y no con negaciones de elementos de la fe presupuestos y vividos.

La tercera crítica se refiere al marxismo: los teólogos de la liberación que hacen uso de algunas categorias de la tradición marxista (especialmen. te de Althusser y de Gramsci) lo hacen a partir de su utilidad práctica, analizando situaciones sufridas por el pueblo; no se trata de una reflexión académica y sisternätica sobre el mar. xismo confrontando con el cristianismo. No existe un interés por Manx como tal. Marx y sus compañeros interesan en la medida en que ayudan a comprender mejor la realidad de la 
explotación y apuntan hacia posibles superaciones del sistema antipopular y excluyente que es el capitalismo. $\mathrm{Si}$ Roma hubiese dialogado con los teólogos de la liberación, si hubiese frecuentado la literatura existente sobre esta acción liberadora, habría tenido la oportunidad de captar la diferencia entre un abordaje teórico del tema y un abordaje práctico sobre la acción liberadora. Habría mucho más para comentar. Nos alcanzan estas indicaciones iniciales y la esperanza de que el documento prometido haga más justicia a la reflexión latinoamericana. Es periférica y se hace bajo condiciones de pobreza, pero puede significar una contribución a la Iglesia y principalmente a los oprimidos del mundo entero que posean una referencia religiosa o cristiana. 


\section{Pablo Richard}

1. Un documento de discernimlento, no de condenaclón. Acogemos con esperanza esta instrucción sobre la Teología de la Liberación, pues no se trata de una condenación, sino de un discernimiento positivo entre las diferentes corrientes de este movimiento teológico.

\section{Preocupación pastoral por los} pobres y su Justlcla. Nos alegra la preocupación pastoral por los pobres, pues la Instrucción exige que "de ninguna manera debe interpretarse como una desautorización de todos aquelios que quieren responder generosamente y con auténtico espíritu evangélico a la opciôn preferencial por los pobres" (Introducciōn). Igualmente nos dice que esta Instrucción "de ninguna manera debe ser interpretada como una aprobación, aun indirecta, dada a quienes contribuyen al mantenimiento de la miseria de los pueblos, a quienes se aprovechan de ella, a quienes se resignan o a quienes deja indiferentes esta miseria" (XI, 1).

Que esta advertencia impida pues toda manipulación de! documento, por parte de los medios de comunicación, para escandalizar o confundir al pueblo pobre y creyente de América Latina (cf. Mrc. 9,42).

3. Identificación fundamental con la Instrucclón. Por obediencia de fe, amor a la lglesia y honestidad intelectual, declaro públicamente mi identificación fundamental con las declaraciones y advertencias de la Sagrada Congregación.

\section{Existe una auténtica teologia} de la liberación. Aceptamos como 'auténtica 'teología de la liberación,' la que está enraizada en la Palabra de Dios, debidamente interpretada" (NI, 7); este "movimiento teológico y pastoral" nace en primer lugar en América Latina (III, 2) para discernir $e$ interpretar, a la luz del Evangelio, "la poderosa y casi irresistible aspiración de los pueblos a una liberación" $(1,1)$.

5. Fundamentos bíblicos de la teología de la llberación. Acepta. mos que "una teologia de la literación correctamente entendida constituye una invitación a los té́logos a profundizar ciertos temas biblicos esenciales, con la preocupación de las cuestiones graves y urgentes que 
plantean a la Iglesia tanto la aspiración contemporánea a la liberación como los movimientos de liberación que le hacen eco más o menos fielmente. No es posible olvidar ni un solo instante las situaciones de miseria dramática de donde brota la interpretación asī lanzada a los teólogos" (IV, 1).

Referente a esta hermenéutica biblles liberadora, concordamos con el documento que dice: "El error no está aqui en prestarle atención a una dimensión política de los relatos biblicos. Estä en hacer de esta dimensión la dimensión principal y exclusi$v a$, que conduce a una lectura reductora de la Escritura" $(x, 5)$.

Aceptamos por lo tanto los fundamentos biblicos y advertencias hermenéuticas ofrecidas por la Instrucción, especialmente sobre la liberación radical del pecado, la ley y la carne para vivir una vida segün el Espiritu; la liberación histórica del Exodo, donde "Dios es reconocido como el Liberador" (IV, 3.4); y la presencia misteriosa de Jesüs en el pobre, según Mt. 25,31-46 (IV.9), que ha constituido la experiencia espiritual más original y fecunda de la teología de la liberación.

6. Maglsterlo y teología de la libereción. Aceptamos la orientación que se nos dirige a los teólogos: "Conscientes del carácter eclesial de su vocación, los teólogos colaborarán lealmente y en espiritu de diálogo con el Magisterio de la Iglesia" (XI, 4). Aceptamos los textos magisteriales del documento $(M)$, pues responden al desafío proclamado por la Instrucción: "Para responder al desafio lanzado a nuestra época por la opresión y el hambre, el Magisterio de la Iglesia, preocupado por despertar las conciencias cristianas en el sentido de la justicia, de la responsabilidad social y de la solidaridad con los pobres y oprimidos, ha recordado repetidas veces la actualidad y la urgencia de la doctrina y de los imperativos contenidos en la Revelación" $(N, 1)$.

\section{Rechazo de una falsa} teologia de la liberación. Rechazamos, con los términos y argumentos de la Instrucción de la Sagrada Congregación, toda producción teológica, que bajo el nombre de "teología de la liberación," propone una "interpretación innovadora del contenido de la fe y de la existencia cristiana que se aparta gravemente de la fe de la Iglesia" $(\mathrm{VI}, 9)$. Especialmente rechazamos toda teología que tenga como raíz la "ideología marxista" o una "hermenéutica dominada por el racionalismo," tal como son interpretadas por la Instrucción $(\mathrm{VI}, 10)$.

Rechazamos igualmente toda teología que pretendiera tomar del maxxismo su núcleo ideológico," que ejercería la función de "principio determinante" de la reflexión teolögica (VIII, 1). Para nosotros la única rá́z de la teología es la vivienda espiritual de Dios en el mundo de los pobres y en la lucha por la justicia. No reconocemos otro principlo determinante de nuestra reflexión teológica que no sea la Palabra viva de Dios interpretada en el seno de la comunidad eclesial.

\section{Uso positivo de las cienclas} sociales en la teología de la llberaclón. Referente a la utilización de las ciencias sociales, reconocemos la afirmación del documento: "Es evidente que el conocimiento científico de la situación y de los posibles caminos de transformación social es el presupuesto para una acción capaz de conseguir los fines que se han fijado. En ello hay una señal de la seriedad del compromiso" (VII, 3). 
Reconocemos igualmente la necesidad de "un examen crítico de naturaleza epistemológica" para superar la "fascinaciốn casi mítica" de la teoría que se impone como necesaria, por el solo hecho de presentarse como "científica" (NIi, 4).

Aceptamos con el máximo rigor el principio establecido por la Sagrada Congregación de que "la utilización por la teología de aportes filosóficos o de las ciencias humanas tiene un valor 'instrumental' $y$ debe ser objeto de un discernimiento crítico de naturaleza teológica. Con otras palabras, el criterio último y decisivo de verdad no puede ser otro, en última instancia, que un criterio teológico" (VII, 10).

9. Rechazo de un marxismo Ideológico y de una determinación política radical de la vida cristiana.

Aceptamos en el caso del marxismo la crítica y el discernimiento como necesarios para discriminar una concepciōn totalitaria del mundo que integra la observación y el análisis de la realidad en una estructura fllosóflea. Ideológica (VII, 6). Rechazamos especialmente el materialismo metafísico y la fllosofía atea. Rechazamos asi un marxismo ideológico que reduce el conocimiento científico, la conciencia, la verdad y la ética a la lógica ne. cesaria y absoluta de la lucha de clases (VIII, 2-7).

Rechazamos igualmente una concepción teórica de la lucha de clases, como ley absoluta, que determinaría todos los campos de la existencia, religiosos, éticos, culturales e institu. cionales (VIII,8).

Rechazamos también una "teologia de la liberación" que negaria la realidad teologal de la fe, esperanza y caridad y que significaría una politización radical de la fe y de los juicios teológicos, subordinándolo todo a un criterio puramente político (IX,5-7).

10. Discernimlento ecleslológlco. Concordamos con los criterlos eclesiológicos de la Instrucción de la congregación romana. Rechazamos, en consecuencia, toda reducción sociológica y política de la Iglesia, que niegue su realidad específica como gracia y misterio de fe $(I X, B)$.

Reconocemos con gozo y esperanza la significación positiva que el documento atribuye a la definición "Iglesia de los pobres" (IX,9) y a la expresión "Iglesia del pueblo" (IX,11). Nos identificamos con el documento cuando propone: "La Iglesia, que quiere ser en el mundo entero la Iglesia de los pobres, intenta servir a la noble lucha por la verdad y por la justicia, a la luz de las Bienaventuranzas, $y$ ante todo de la bienaventuranza de los pobres de corazón" $(X I, 5)$.

Nos alegramos que la Instrucción reconozca positivamente "una corrección fraternal respecto a los pastores de la Iglesia cuyo comportamiento no refleja el espiritu evangélico de servicio y se une a signos anacrónicos de autoridad que escandalizan a los pobres" $(I X, 13)$. Sería, sin embargo, un absurdo teológico suponer una teologia de la liberación que "denuncia la jerarquía y el Magisterio como representantes objetivos de la clase dominante que es necesario combatir" (IX,13 y $X, 1)$. Igualmente absurdo sería una teología que considerara las relaciones entre la jerarquĩa y la "base" como "relaciones de dominación que obedecen a la ley de la lucha de clases" $(X, 15)$. Si surgieran tales teologías falsamente liberadoras, jamás nos identificariamos con ellas. 
11. Discernimiento crlstológlco. La teologĩa de la liberación auténtica, con la cual nos identificamos, reconoce en toda su integridad la persona de Nuestro Señor Jesucristo, verdadero Dios y verdadero hombre $(X, 7)$ y confiesa siempre su fe en el "Verbo encarnado, muerto y resucitado por todos los hombres" $(X, 11)$. Valorizamos, contra una hermenéutica racionalista, al Jesús de la historia, sin oponerlo jamás al Cristo de la fe. El rescate del Jesús de la historia, con toda su radicalidad evangélica, no significa reducirlo a un hecho puramente político, donde Jesüs no sería măs que un simbolo $(X, 11-12)$.

12. Valoración de la práctica para la teologia de la llberaclón. Reconocemos que la Instrucción rescata lo positivo de la teología de la liberación referente a la "práctica:" " "La experiencia de quienes trabajan directamente en la evangelización y promoción de los pobres y oprimidos es necesaria para la reflexión doctrinal y pastoral de la Iglesia. En este sentido, hay que decir que se tome conciencia de ciertos aspectos de la verdad a partir de la praxis, si por ésta se entiende la práctica pastoral y una práctica social de inspiración evangélica" (Xl, 13).

13. Oportunldad de valorlzar clertos elementos teológlcos. Concordamos con el documento de la congregación para la doctrina de la $f e$ en la oportunidad de acentuar siempre la "trascendencia y gratuidad de la liberación en Jesu. cristo," la "verdadera naturaleza de los medios de salvación," la "verdadera significación de la ética," el "sentido auténtico del pecado, la necesidad de la conversión y la universalidad del amor fraterno;" insistimos con el documento en el carácter específico del reino de Dios, en las trascendencia de la persona humana y en el respeto a la religiosidad del pueblo $(X \mid, 17)$.

14. Puntos críticos en la Instrucclón de la congregación romana.

a) No se valoriza la espiritualidad, que es la raíz específica y la ma. yor riqueza de la teología de la liberaciōn.

b) Está ausente en la Instrucción lo que Puebla (No. 1147) llama "el potencial evangelizador de los pobres," es decir, la capacidad del pueblo pobre y creyente latinoamericano de discernir, expresar y reflexionar teológicamente el sentido de la fe.

c) Se desconoce la importancia fundamental y determinante de las Comunldades Ecleslales de Base, que es el espacio eclesial donde ha nacido y madurado la teología de la liberación.

d) La perspectiva global del documento de la Sagrada Congregación para la Doctrina de la $\mathrm{Fe}$ es ajena y extraña al Tercer Mundo. Se desconoce la tradición intelectual y la metodología de trabajo que con tanto esfuerzo $y$ sacrificio ha surgido en los paises pobres. Entre nosotros existe una nueva manera de pensar y de hacer teologia, que es ignorada por el documento.

e) En la articulación de la teología con las clencias sociales el documento establece principios básicos que nosotros valoramos, pero tememos que el documento oriente la discusión de esta articulación en un sentido equivocado. No quisierámos que la Iglesia in- 
terviniera en apreciaciones cientificas, repitiendo su trágica equivocación con Galileo Galilei y tantos otros.

f) Encontramos en el documento muy poco espiritu critico y capacidad de discernimiento frente a tantas doctrinas dominantes que pueden ser más peligrosas para la fe que ciertas corrientes del marxismo. Nos referimos a las doctrinas neo-positivistas y a ideologias neo-conservadoras, como asimismo a las perversiones ideológicas de la doctrina de la seguridad nocional. Quisiéramos una Iglesia que tuviera especialmente miedo de equivocarse con las ideologías del mundo rico, y no una Iglesia con tanto miedo de equivocarse del lado de los pobres en sus intentos de elaborar una ciencia y una doctrina social liberadoras.

g) Tememos que la Instrucción sobre algunos aspectos de la teologia de la liberación, que es un documento positivo de discernimiento y no de condenaciōn, sea mani- pulado para legitimar una persecusión contra el pueblo cristiano - sus comunidades y teólogosque hoy toma conciencia de su dignidad y del sentido evangélico de la justicia. Lamentamos profundamente que ya exista un "resu. men del documento," elaborado por la congregación romana, que se orienta peligrosamente en tal sentido, al suprimir la preocupación pastoral por los pobres y todas las referencias positivas del texto original.

Quisiéramos terminar adhiriéndonos a la declaración de nuestro obispo Monseñor Román Arrieta, presidente de la conferencia episcopal de Costa Rica y del secretario episcopal de América Central, sobre la Instrucción de la Sagrada Congregación para la Doctrina de la Fe, especialmente cuando dice: "la opción preferencial por los pobres, lejos de amenazar con dividirnos, se convertirá en el núcleo más fuerte de nuestra cohe. sión y unidad." 


\section{Ronaldo Muñoz}

1. En primer lugar, reconozco con gratitud la vigorosa y fundamentada reafirmación que hace el documento de la Santa Sede del compromiso evangélico de la Iglesia con la aspiración de los pobres y oprimidos del mundo a la llberación, y su advertencia de que "de ninguna manera podrá (el mismo documento) servir de pretexto a quienes se atrincheran en una actitud de neutralidad y de indiferencia ante los trágicos y urgentes problemas de la miseria y de la injusticia" (Introducción, capítulo I, III, IV, $V$ y XI, 1-2).

2. Me adhiero lealmente y en obediencia responsable a las "Orlentaclones" pastorales con las que el documento culmina (capitulo XI). En particular, me adhiero con convicciōn al párrafo 4 del mismo capítulo: "Consciente del carácter eclesial de su vocación, los teólogos colaborarán lealmente y en espíritu de diślogo con el Magisterio de la Iglesia. Sabrán reconocer en el Magisterio un don de Cristo a su Iglesia y acogerản su palabra y sus instrucciones con respeto filial."

3. Con mayor razón, me adhiero sin reservas a los Julclos doctrinales sobre la fe contenidos en el cuerpo del documento. Las tesis o interpretaciones "reductoras" que alli se describen como desviaciones y corrupción de la fe cristiana, efectivamente lo son, como debe ser evidente para todo fiel católico. Así, por ejemplo, desconocer la realidad del pecado como raíz de toda esclavitud humana, interpretar el Evangelio como un mensaje de liberación puramente socioeconómica y política, negar la fe en el Verbo encarnado que murió y resucitó por todos los hombres, identificar a Dios y la historia y "definir" la fe como fidelidad a la misa, considerar a la Iglesia como una organización social meramente humana, etc. (Introducción, capítulos Vl, IX y X).

4. Me adhiero también a los grandes principlos antropológlcos, soclales y étlco-polítlcos que el documento reafirma en cuanto implicados en la concepción cristiana del hombre y de la historia. Asi, por ejemplo, la necesidad de conversión de las personas para llegar a una sociedad nueva, la convicción de que la indispensable transformación revolucionaria de las estructuras capitalistas y dic- 
tatoriales no produce automáticamente una sociedad justa y fraterna, la ne. cesidad del discernimiento evangélico de las concepciones "cientificas" de la economía y de la sociedad, el rechazo de los caminos de acción que implican "el recurso sistemático a la violencia," etc. (Capítulos II, VIII Y XI, 5-11).

5. Reconozco que la teología latinoamericana -confrontada en los dos últimos decenios con graves y urgentes desafios para la fe y la prä́ctica cristianas- ha presentado a veces expresiones ambiguas y desarrollos poco maduros. Pero, por lealtad eclesial, debo dar testimonio de que no conozco, en Chlle ni en América Latina, teoologos que sostengan las interpretaciones "reductoras" de la fe descritas por el documento, ni que nieguen esos grandes principios de la concepción cristiana del hombre y de la sociedad.

6. Que tan graves desviaciones sean imputadas - sin mayor precisión- a "ciertas corrientes" de la teología latinoamericana, proyecta una sospecha sobre la fidelidad de todo ministerio teológico que pueda ser inscrito en la "teología de la liberación," aunque - como es el caso de la gran mayoría en América Latinaesos télogos hayan trabajado siempre en leal colaboración con la jerarquía de sus iglesias. Por responsabilidad pastoral frente al pueblo de Dios y por justicia para los teólogos, me parece indispensable que se acla. re con precisión a qué teólogos se hacen tan graves imputaciones $y$ con qué fundamento concreto en sus escritos y enseñanzas, dándoles a ellos la oportunidad de defenderse, explicarse mejor o rectificarse.

7. El documento de la Santa Sede parece sugerir que tal aclaración sería superflua, puesto que la teología de la liberación -o algunas corrientes de la misma cuyos limites no se precisanestaría viclada de raíz en virtud de estos dos principios:

a) Que el maxismo sería un sistema totalizante de tal fuerza lógica y persuasiva, que sería imposible admitir elementos de sociologia manxista, sin ser arrastrado a admitir toda la visión filosófica y la práctica histórica del marxismo, hasta sus formas más ateas, antihumanas y violentas (Introducciōn y capítulo VII).

b) Que la teología de la liberación "debe ser criticada no en tal o cual de sus afirmaciones, sino en el nivel del punto de vista (marxista) de clase que adopta a priori y que funciona en ella como un principio hermenéutico determinante" (capítulo $X, 2$ ).

8. En virtud de esos dos principios, no parece interesar tanto lo que los teólogos de la liberación piensan y enseñan "de hecho," cuanto la construcción (hipotética) de lo que "se supone" que piensan. Con lo cual, me atrevo a preguntarme si el documento no habrá sido escrito con la misma actitud no-dialogante que se atribuye a los télogos impugnados: "Argumentos y enseñanzas no son examinados en sí mismos, pues sōlo reflejan los intereses de clase. Por ello, su contenido es decretado, en principio, falso" (capitulo X,1).

9. Sobre el primer príncipio (a) mencionado en mi punto 7 , creo mi deber explicar lo siguiente:

1) Que no logro ver cómo un tal principio pueda ser enseñado magisterialmente en nombre de la tradición de la Palabra de Dios re- 
velada. Y creo legítimo preguntarse si no podría constituir măs bien una apreciación histórica, ideológicamente condicionada, análoga a las apreciaciones sobre los de. rechos humanos y la democracia que formularon los papas anteriores a León XIII.

2) Que nuestra experiencia en América Latina más bien desmiente ese principio, ya que es aqui bastante corriente en el pueblo cristiano la asimilación serena de perspectivas maxistas de los conflictos sociales, sin experimentar por eso la tentación de adop. tar una filosofia maxista global.

3) Que, por el contrario, el manismo nos deja bastante en eviden. cia sus grandes vacios como concepción global, y -particularmente en sus corrientes positivistas y leninistas- sus graves contradicciones históricas y ético-politicas.

4) Que los teólogos latinoamericanos sostenemos la creeencia y ve. rificamos en nuestra práctica pastoral: que el Evangelio es más globalizante y más fuerte que el marxismo en cualquiera de sus formas; que por lo mismo, cuando los creyentes confrontamos honesta y críticamente nuestra fe con el maxismo, es la fe la que "asimila" elementos del manxismo en une síntesis cristiana, y no viceversa; $y$, que este mismo fenómeno es coherente con lo que ha ocurrido a lo largo de toda la historia de la Iglesia cuando el men. saje cristiano es confrontado seriamente con las grandes corrientes del pensamiento humano.

5) Que en esta linea nos sentimos confirmados por la práctica del magisterio pontificio reciente, el que asimila elementos importantes de antropología y sociología maxista. Así, en las encíclicas de Juan Pablo Il: la "alienación" que sufre el hombre de los frutos de su trabajo, como "el capítulo principal del drama de la existencia humana contemporănea" (RH, 15); el reconocimiento de que "un mecanismo defectuoso está en la base de la economía contemporánea y de la civilización materialista, el que no permite a la familia humana alejarse de situaciones tan radicalmente injustas" $^{\prime \prime}$ (DM, 11); la distinción entre "trabajo objetivo" y "trabajo subjetivo," la constación del conflicto profundo entre el minoritario "mundo del capital" y el mayoritario "mundo del trabajo," la insistencia en la indispensable solidaridad de los trabajadores en su lucha por un orden social justo, etc. (LE, 5,6,8,11,20).

6) Que entre nosotros la confrontación cristianismo-manxismoespecialmente en grupos más politizados de clase media y (para Chile) en el período 1967-73- no siempre ha sido llevada con suficiente madurez y lucidez crítica. Que los teólogos latinoamericanos somos conscientes de los desafíos que presenta esta cuestión, y estamos trabajando en ello en conjunto con diversos grupos cristianos y en comuniớn con nuestros Pastores.

10. Sobre el segundo principlo (b) mencionado en mi punto 7, debo aclarar que los únicos "principios hermenéuticos determinantes" para nuestra lectura de la Palabra viviente de Dios, son estos dos, que por la na- 
turaleza misma del Evangelio y el seguimiento de Jesucristo, consideramos inseparables y correlativos: la comunión eclesial y la liberación de los oprimidos. Sobre cada uno de éstos, debo explicar lo siguiente:

1) Que la comunión eclesial la consideramos fundamentalmente en el nivel básico de la comunión de hermanos que comparten la fe y la oración, la misión evangelizadora y el servicio; pero también y necesariamente, en el nivel de la pertenencia a una iglesia jerárquicamente organizada, en comunión con la Iglesia universal con su Tradición y su Magisterio. Que, precisamente, nuestro ministerio teológico tiene como matriz y preocupación prioritaria, la experiencia espiritual y la práctica liberadora de comunidades eclesiales que viven la comunión católica desde las mayorias oprimidas.

2) Que la llberación de los oprimldos es para nosotros en concreto la de las mayorías empobrecidas y reprimidas de nuestro continente, con sus rostros personales y con toda su compleja realidad socio-económica, étnico-cultural y religiosa; en su "liberación" la entendemos $y$ queremos servirla en toda su in- tegridad humana $y$ cristiana, $y$ con todas sus proyecciones; que situados en el "lugar social" de las mayorías pobres y mirando la sociedad global con su perspectiva, pensamos correr menores riesgos de una visión parcial e ideologica que si estuviéramos en el "lugar" de los sectores privile. giados; que, caminando con los pobres y oprimidos de la tierra, damos testimonio con alegría de la presencia liberadora que alli reconocemos del Dios de Jesucris. to, $y$ de la mayor esperanza que de ello se sigue para la humanidad entera; que para la liberación de los oprimidos del "Tercer Mundo" y de toda la humanidad, no podemos dejar de denunciar y combatir evangélicamente el tremendo poder idolátrico, explotador y genocida del sistema geo-económico, geo-político $e$ ideológico que tiene su centro en el llamado "Occidente cristiano."

Santiago de Chile, $\theta$ de septiembre de 1984.

Día del natalicio de Marla.

Día del traslado de los restos de nuestro misionero martir, P. Andrés Jarlan, testigo de Cristo entre los oprimidos, asesinado hace cuatro dias por la represión. 


\section{Jon Sobrino}

La Instrucción sobre algunos aspectos de la teología de la liberación tiene como fin específico "atraer la atención de los pastores, de los té́logos y de los fieles sobre los graves peligros en que incurren algunas de las teologias de la liberación" (Introducción). Como fiel y como téologo he leído la Instrucción. Como fiel en primer lugar, pues más primigenia y más importante que la teología es la misma vida de la Iglesia y en América Latina, en concreto, los sufrimientos y las esperanzas de los pobres por los cuales la Iglesia debe hacer una opción preferencial, y la fe, la esperanza, el compromiso y el martirio de los pobres creyentes que la lglesia debe recoger y en lo que también se debe inspirar para realizar su misión. Esa es la óptica principal desde la que he leido la Instrucción. Pero la he leído también como teólogo y como teólogo afectado porque en la Instrucción. aunque no se citen textos ni nombres, se recogen afirmaciones de un escrito anterior del Cardenal Ratzinger en el cual se me cita textualmente.

Mons. Quarracino ha dicho que por su misma naturaleza la Instrucción "debiera provocar un diálogo profundo y sereno entre télogos en el interior de la Iglesia." Con ese espiritu de diálogo y con el deseo de que el de. bate generado produzca más bienes que males para la teología, para la Iglesia y sobre todo nara los pobres de América Latina quisiera ofrecer las siguientes reflexiones.

1. La Instrucción me parece sumamente importante por lo que dice de la liberación y de la teología. Por lo que toca a la liberación, la Instrucción reconoce la espantosa situación de opresión del continente -opresión que descriptivamente es analizada comenzando con la opresión histórica y socio-económica-, la justa y legítima aspiración de los pueblos a su liberación y de ahi la urgente e ineludible obligación de la Iglesia de hacer la opción por los pobres, que no debe ser de ninguna forma mitigada ni excusada por los peligros que denuncia la instrucción. Por lo que toca a la teologĩa, acepta la posibilidad y, novedosamente, impone la exigencia de hacer objeto suyo la fiberación. Más aũn, reconoce a veces implicita, a veces explicitamente que lo que ya 
hay de teología de la liberación ha servido de hecho para redescubrir importantes contenidos de la Escritura; que algún tipo de análisis social es legítimo y necesario en la teología; que incluso la práctica, en cuanto práctica pastoral y en cuanto práctica social guiada por el evangelio, es una ayuda eficaz para el quehacer teológico. Reconoce que la teología de la liberación no puede ser comprendida como teología regional, aplicación ética de una teología ya constituida con independencia lógica del tema de la liberación, sino como verdadera teología sistemática que trata y da respuesta a toda la temática teológica.

Esto significa, de hecho, que en la Iglesia ya está in posesione lo que hace 20 años no lo estaba y que el movimiento de la teología de la liberación ha sido insustituible para ello y más eficaz que otras teologías e incluso que la doctrina o enseñanza social de la Iglesia, la cual ha ido abriéndose al tema de la liberación a medida que objetivamente ha sido forzada por el movimiento de la teología de la liberación. Indudablemente, según la ins. trucción, habră que cuidar, purificar el tema de la liberación; pero ésta se ha hecho ya referencia obligada $y$ obligante para la Iglesia y para la teología. En principio, la liberación de los pobres se ha convertido en tema central de la misión pastoral y de la teoría teológica de la Iglesia.

Pero junto a este reconocimiento, en la Instrucción hay una larga serie de advertencias y acusaciones -aunque se evita el lenguaje condenatorio- hacia una teologia de la liberación que se inspira en el marxismo y en su teoria y práctica de la lucha de clases que viciaria de raiz todos los contenidos teológicos y conduciría adernás a peores esclavitudes. Esa teología sería, por lo tanto, espúrea e ineficaz. El listado de manipulaciones y errores que de ahí se derivarian es verdaderamente impre. sionante, tal como aparece en los capitulos VII-X de la Instrucción. Por recordar los más nefastos y fundamentales, la teología de la liberación haría desaparecer el carácter transcendente de la distinción entre el bien y el mal, haría a Dios superfluo en favor del dinamismo propio de la historia y de la lucha de clases, negaría la divinidad de Cristo, la novedad radical del Nuevo Testamento, la realidad sacramental de la Iglesia y un largo etcétera. Leidos y releidos estos capítulos producen escalofríos a cualquier cristiano y a cualquier teólogo. Si la teología de la liberación o cualquier otra dicen lo que la Instrucción dice que dicen entonces operarian realmente un vaciamiento fundamental de la revelación y de la fe, bien por absoluta incompetencia, bien por ingenuidad o bien porque habrían abdicado realmente de la fe cristiana.

La Instrucción no dice con claridad si, en qué medida, cuấn explícita o implicitamente aparecen esos crasos errores en los teólogos de la liberación. No se sabe por ello exacta. mente si la Instrucción es condena objetiva de lo que ya se ha escrito o una advertencia en lenguaje hiperbólico para que no se lleguen a escribir tales cosas. Pero ahí están formuladas. Y si todo fiel cristiano tiene que estar dispuesto a dar razón de su esperanza, todo teólogo tiene que estar dispuesto, ademăs, a dar razón de su fe y de la ortodoxia de su teología, bien porque se lo exija el Vaticano o el mãs humilde de los campesinos. Por ello, con ocasión de la Instrucción tan publici- 
tada mundialmente, varios teólogos han reafirmado su fe y su ortodoxia, como puede verse en este número de la revista, y en relación explícita a lo que la Instrucción exige de fe y de ortodoxia. Personalmente sólo puedo anadir a lo que ya han dicho otros que el maxismo no es en modo alguno principio determinante de $\mathrm{mi}$ teologia y que he procurado siempre mantener y potenciar las verdades fundamentales de la fe que la Instrucción ve puestas en duda. En un punto de suma importancia dice la Instrucción: "Es cierto que se conservan literalmente las fórmulas de la fe, en par. ticular la de Calcedonia, pero se le atribuye una nueva significación, lo cual es una negación de la fe de la Iglesia. Por un lado se rechaza la doctrina cristológica ofrecida por la Tradición, en nombre del criterio de clase; por otro, se pretende alcanzar el "Jesús de la historia" a partir la experiencia revolucionaria de la lucha de los pobres por su liberación" $(X, 9)$.

No conozco a ningún teólogo de la liberación connotado que haga tal tratamiento de la fórmula de Calcedonia ni del Jesús de la historia. Personalmente sólo puedo añadir que no ha sido esa mi intención; que no lo sea asi objetivamente, es cosa de otros el juzgarlo. El P. Alfaro, al menos, así lo ha mostrado en un articulo publicado en el número anterior de esta revista.

La Instrucción se ha convertido en ocasión y en necesidad práctica de que los teólogos reafirmemos nuestra fe y nuestra adhesión a la dactrina ortodoxa de la Iglesia, aunque en la Instrueción ésta sólo parece muchas veces sub specle contraril a traves de lo que condena. Así lo hacemos con gusto; reafirmamos y nos adherimos a la fe de la iglesia. A otros toca y especificamente a la Congregación para la Doctrina de la Fe juzgar de la objetividad de nuestra teologla. Sólo deseariamos que en su proceder, y en el de los teólogos, fuese una realidad el "presupuesto" que pone San Ignacio al comienzo de los Ejercicios Espirituales: "Para que asi el que da los exercicios spirituales como el que los recibe, más se ayuden y se aprovechen, se ha de presuponer que todo buen christiano ha de ser mäs prompto a salvar la proposición del próximo que a condenarla; y si no la puede salvar, inquira cómo la entiende, y si mal la entiende, corrijale con amor, y si no basta, busque todos los medios convenientes para que, bien entendiéndola, se salve" (n.22).

2. Dicho todo esto con sinceridad, sine ira et studio, y si lo que hemos dicho es verdad, entonces algo muy importante está ocurriendo para la Iglesia y para la teología con la revalorización de la liberación, pero algo también preocupante y peligroso para la teología, la Iglesia y la liberación de los pobres. Pues, ¿cómo es posible que, por una parte, el Vaticano haga tan graves acusaciones, que sienta la imperiosa necesidad de escribir y difundir masivamente un documento universal para contrarrestar los efectos del error, y por otra parte, que los télogos afectados nieguen que les afecte, se adhieran sin reservas a la verdad contraria a los errores enumerados $y$, más aún, afirmen que una finalidad importante de su teología sea la de posibilitar y potenciar, en un continente de pobres creyentes, la fe y la fe ortodoxa?

Esta situación es verdadermente anómala y peligrosa. Tratando de entender desde América Latina por qué se ha escrito la Instrucción de esta for- 
ma, hay que empezar reconociendo que la teologia de la liberación tiene limitaciones, que ha puesto énfasis en algunos temas que han podido ser interpretados como reduccionistas. Tampoco se puede excluir que la teología de la liberación haya podido ofrecer a algunos la ocasión para una lectura más exclusivamente politizante de la Escritura y de la fe, aunque ello se deba no a la naturaleza y dinsmica interna de la teología de la liberación, sino a disposiciones y expectativas previas de algunos de sus lectores, como sucede con otro tipo de teologias. Estas realidades, magnificadas exageradamente, han podido llevar a escribir la Instruccción. Tambiện hay que tener en cuenta que la teología de la liberación ha sido eficaz para expresar la novedad de la Iglesia Latinoamericana desde Medellín, novedad que por si misma hace ya difícil su captación y la de la teología que la expresa, y ha cooperado a que la Iglesia sea más evangélica, lo cual siempre tiene también consecuencias desagradables como la desunión que genera intraeclesialmente a todos los niveles, porque el pecado del mundo divide a la Iglesia, los gravisimos problemas con gobiernos, con quienes en tanto autoridad la Iglesia desea estar a buenas, las amenazas, la persecución, los asesinatos de obis. pos, sacerdotes, religiosas y demás fieles cristianos. Evitar o minimizar esas consecuencias desagradables que la teologia de la liberación ha explicitado, por ser evangélicas, ha podido ser otro de los motivos. Quizás esté de fondo el interés por mantener al mundo occidental, convencionalmente democrático y culturalmente cristiano, como el mundo connatural a la Iglesia y a Dios, cosa que cuestiona la teología de la libera- ción no primaria y necesariamente en nombre del maxismo, sino en nombre del evangelio.

Todo esto ha podido llevar a que en el Vaticano se tome por error lo que es limitación, se tome por reduc. cionismo mutilante de la fe lo que es énfasis, se tome por finalidad lo que es ocasión no buscada, se tome por juego al marxismo lo que es fidelidad evangélica, se tome por ataque 10 que es profecía y verdadero amor a la Iglesia.

Por estas y otras razones la Instrueción desfigura seriamente a la teología de la liberación; parece no conocerla bien en lo que cita supuestamente de ella y no conocerla bien en aquello a lo que ni siquiera alude. El silencio sobre la ingente produc. ción sobre espiritualidad en la teología de la liberación es un ejemplo clamoroso. Pero lo más serio es que, leída desde América Latina, la Instrucción parece no poder entender la teología de la liberación que critica, por la diferencia en método y talante teológicos. La Instrucción sólo parece conocer un método fundamental, mientras que los té́logos de la liberación son más conscientes de su diversidad, precisamente porque algunos tienen la experiencia teológica del primer mundo por nacimiento y/o por formación y la experiencia teológica de América Latina. La instrucción adopto un método teológico fundamental unilateralmente desde la doctrina hacia la realidad, desde lo universalidad hacia la concreción latinoamericana. Los teólogos de la liberación conocen ese método y no lo excluyen, al contrario usan los aportes positivos que ha producido. Pero afiaden y lo complementan con el movimiento inverso: desde la reali- 
dad hacia la doctrina, desde la experiencia de la realidad y la práctica sobre ella; con lo cual no están cayen. do en un sociologismo porque admiten y exigen un tratamiento también estrictamente teológico de la realidad. Eso es lo que significa una teología fundamentada en los signos de los tiempos. Lo que haya de doctrina previa es importante para descubrirlos, pero no suficiente; y una vez descubiertos son doctrinizables teológicamente y potencian doctrinas anteriores. Dicho con toda sencillez, a la teologia le toca hablar desde lo que ya sabe, pero le toca aprender desde la realidad tal como se le va manifestando, lo cual suele modificar y potenciar su hablar previo.

Pero además, y aquí esta, creemos, lo más diferenciador, la teología de la liberación acepta y asume lo que sorprendente y admirablemente dijo Puebla sobre "el potencial evangelizador de los pobres." Estos no son sólo destinatarios privilegiados del amor de Dios, sino también de su manifestación, añade la teología de la liberación; y no debieran ser sólo destinatarios previlegiados de la acción de la Iglesia, sino inspiradores de su fe $y$, por ello, tambiên de su teología.

Estas afirmaciones pudieran ser aceptadas teórica y doctrinalmente, pero se convierten en afirmaciones reales cuando se tiene una experiencia real de ello. Los teólogós de la liberación afirman en general que tienen experiencia de ello, que esa experiencia les ha ayudado a hacer teología para la actualidad, pero también para recuperar lo central de teologías pasadas y de la misma revelación de Dios. Afirman, por lo tanto, que la revelación de Dios y la doctrina basada en ella son insustituibles en la teología, pero afirman también que el mundo de los pobres, en su realidad, no sólo en su concepto, en su interpelación y en su fe realizada es tambiên insustituible para la teología.

Aquí está la diferencia de fondo al nivel estrictamente teológico, junto a otras diferencias motivadas por intereses, gustos o disgustos. Pero para captar la diferencia y verla como enriquecedora hay que tener experiencia de la realidad y de la fe de los pobres, y de su potencial también para la teología.

Si no se capta esa diferencia, entonces una misma afirmaciōn puede ser leída muy diversamente, como por ejemplo el significado preciso de la "muerte política" de Jesús, aludido en la Instruccción. Los cristianos creyentes de América Latina no dudan de que el asesinato de Mons. Romero $y$ de tantos miles de creyentes fue una muerte política; es decir, que fueron asesinados por las consecuencias políticas de sus palabras y acciones, que tocaron y amenazaron a los idolos de la muerte. Históricamente estos cristianos no fueron asesinados por recitar el credo, sino por sus prácticas históricas. Pero los cristianos creyentes de América Latina no concluyen de ahi que esa muerte fuese sólo política o reductivamente política. Para ellos, los asesinados son hombres y mujeres de gran fe y esperanza, creyentes consecuentes y seguidores de Jesús hasta dar la vida por los hermanos y testigos explícitos - con la explicitud de los hechos mucho más real que la de sólo las palabras- de la fe en Dios y de la normatividad ültima de su Hijo Jesucristo. Por ello, esas "muertes políticas" son mucho más que políticas; abren a la comprensión de la totalidad de la fey 
animan a poner en práctica la totalidad de la fe. En este contexto real, hablar de que la muerte de Cristo fue política no tiene ningün sentido reduccionista, aunque desenmascare una interpretación puramente espiritualista de la muerte de Jesús sin causas históricas. Hablar de la muerte política de Cristo es,además de mantenerse fiel a la historia, el modo de relacionar seriamente a Cristo desde el final de su vida con contenidos sumamente importantes de su vida: su anuncio del reino de Dios, su opción por los débiles de este mundo, su profecia, etc., pero también su fidelidad al Padre y su absoluta fidelidad en el silencio de la oración del huerto $y$ de la cruz. La muerte política de Jesús es entonces una forma importante de dar radicalidad a la actividad y a la persona de Jesús de Nazaret; pero también una forma de comprender la radicalidad de la afirmación de la fe: que a ese Jesús ha resucitado el Padre.

$Y$, en la lógica de la fe, que ese Je. sús resucitado es el Cristo, el Hijo de Dios. Puede parecer paradójico desde otras latitudes, pero en América Latina los cristianos que más recalcan que la muerte de Cristo fue en verdad política son los que más y mejor afirman que ese Cristo es verdaderamente el Hijo de Dios. Lo harán con formulaciones sencillas y novedosas al llamarle El liberador, nuestro ünico liberador como dicen en sus cantos; lo hacen sobre todo cuando en el seguimiento de Jesús saben que les va la vida y por él la arriesgan.

3. Dado lo que está en juego es importante que se supere esta situación anómala; que se potencie la teología de la liberaciōn, lo cual ha sido hasta ahora aporte de la propia teología de la liberación latinoamericana, y que se avise de peligros, lo cual ha sido el aporte más específico de la Instrucción. Para ello es necesario que se entable un verdadero diálogo dentro de todo el pueblo de Dios y para su bien, en el cual ambas instancias cooperen con lo mejor y lo más específico de cada una.

Hasta ahora el diálogo no ha sido fácil y la misma Instrucción es prueba de ello. En el intervalo entre la publjcaciōn del primer escrito del Cardenal Ratzinger y la Instrucción, varios teólogos de la liberación y otros teólogos han mostrado con argumentos convincentes en mi opinión que muchas afirmaciones del primer escrito sobre los teólogos de la liberación no son correctas; sin embargo esas afirmaciones se mantienen en la Instrucción. Esto significa que no se ha escuchado, de hecho, a los teólogos en un momento tan importante.

Por su parte, en la Instrucción se dice que es difícil o casi imposible dialogar con los teólogos de la liberación. Ya hemos mencionado antes la dificultad objetiva de la Instrucción de captar lo que dice la teología de la liberación; pero eso no debe llevar a transformarla en dificuldad subjetiva, como si fuese reaimente dificil entrar en contacto fraternal con ellos. Por lo que conozco, varios teólogos de la liberación han cooperado muy en se. rio con los obispos y cuando se les ha llamado la atención desde el Vaticano han contestado con honradez y docilidad. No hay que olvidar el ejemplo de un buen número de ellos en Puebla cuando, impedidos de participar oficialmente y ante la expectativa de organizar un anti-Puebla, reaccionaron con docilidad y servicialidad, en ningún momento se mostra- 
ron antijerárquicos y sólo desearon cooperar al mejor éxito de Puebla. Personalmente sólo puedo añadir que he aceptado siempre y respondido al diálogo con el Vaticano cuando desde alli se me han hecho observaciones a mi teología. Quisiera añadir también que cuando el P. Arrupe explicitamente y Mons. Romero con la exigencia de su ejemplo me pidieron fidelidad total al evangelio, explicitar más los aspectos transcendentes y personales de la fe, recogí esas peticiones y las agradecí.

Un verdadero diálogo en torno a la liberación y su teología es posible y creo que puede ser muy fructifero. A la teología le toca por su propia natuleza proponer novedosamente las reflexiones que van surgiendo desde las exigencias de la realidad y desde la fe de los pobres. Al magisterio le toca encauzarlas, purificarlas, avisar de peligros y errores, subsanar olvidos desde lo que la Iglesia ha ido acumulando en lo mejor de su tradiciôn y animar también a los teólogos.

En cualquier caso, el diálogo es necesario por lo que está en juego. Está en juego el futuro de los pobres, el futuro de la Iglesia y el futuro de la fe. El futuro de los pobres depende de muchas cosas que no son la Iglesia, pero ésta puede y en cualquier caso debe trabajar para que sea un futuro más humano y mâs de acuerdo a la voluntad liberadora de Dios hacia los pobres. Para ello la Iglesia debe trabajar pastoralmente y con la mayor lucidez teórica.

Pero está también en juego el futuro de la fe. Nadie sabe lo que puede ocurrir en el continente latinoamericano cristiano dentro de cincuenta o cien años. No se sabe qué impacto puedan tener movimientos de secularización anălogos a los del primer mundo o movimientos liberadores y revolucionarios, pero pueden cambiar el ambiente religioso latinoamericano. Algunos piensan que el mejor modo de preservar de un cambio importante en lo religioso es mantener y aumentar la seguridad a todos los niveles doctrinales y admnistrativos y propiciar un ambiente cultural cristiano. Esto puede tener éxito, pero pudiera no tenerlo. La teología de la liberación cree que el futuro de la $\mathrm{fe}$, en cuanto depende de hombres, se asegura más bien poniendo en práctica la radicalidad del evangelio, la solidaridad con los pobres del continente, el acompañamiento en sus momentos difíciles y en sus propias luchas por la liberación. Todo ello habrá que hacerlo cristianamente, pero sin ello la Iglesia puede ir perdiendo credibilidad ante los pobres y ante quienes luchan por su liberación, y la fe pudiera ir perdiendo poco a poco su obviedad ambiental actual.

Desde este punto de vista, lo que más me preocupa de la Instrucción y lo que hay que esclarecer con la mayor objetividad posible es lo que se dice en la introducción: que los peligros de que se van a advertir son "ruinosos para la fe y para la vida cristiana." Lo son indudablemente, tal como son presentados. Pero hay que preguntarse si la teologia de la liberación es realmente ruinosa para la fe. En mi opinión no sólo no es ruinosa, sino que, de hecho, ha ayudado a mantenerla y acrecentarla entre los pobres y sobre todo entre aquellos gue han recuperado su conciencia y buscan su liberación, quienes teóricamente hubieran podido acudir a otras fes, a otras ideologías, si su tradicional fe cristiana no les hubiera sido ex- 
puesta novedosamente. Creo que no se puede dudar del servicio de la teología de la liberación a la fe de estos pobres, y también de otros dubitantes de corte liberal o positivista. La teología de la liberación ha ayudado a la liberación de los pobres, pero taimbién ha ayudado a mantener la fe en Dios. Indudablemente es una teología antiidolátrica, pero tambiên una teología eficaz para detener el ateísmo tal como se presenta y se puede ir presentando en nuestro continente.

Con todas sus limitaciones y peligros, la teología de la liberación ha dado credibilidad a la Iglesia y a la fe. Ha conseguido que, al menos negativamente, no se haga realidad la terrible acusación de la Escritura: "Por su causa el nombre de Dios es blasfemado entre las naciones." Ha conseguldo positivamente mostrar que con
Dios también se humaniza el hombre y anima siempre a mostrar que con Dios se humaniza más y mejor al hombre, que el evangelio es en verdad una buena noticia para la libera. ción y para la transformación interior de los hombres y mujeres pobres del continente. Mantener, purificar, incrementar ese núcleo absolutamente fundamental es la tarea de la teología de la liberación, del magisterio de la Iglesia y de todo el pueblo de Dios. Esa es, creemos, la urgencia y la mayor responsabilidad actual.

Con ello la teología de la liberación será a la vez un modo eficaz de cumplir la imperiosa exigencia de Dios a la Iglesia de optar por los pobres y trabajar por su liberación y un modo de mantener la credibilidad de la lglesia y de la fe y trabajar asi por su futuro. 


\section{Julio de Santa Ana}

El día 12 de junio del año en curso, Juan Pablo ll visitó el Consejo Mundial de Iglesias. Fue la segunda visita de un pontífice romano luego de que en 1969 Pablo VI visitara por primera vez este organismo. Esta sirvió para reafirmar, una vez más, la voluntad de las Iglesias de encontrar caminos para una mayor convergencia entre ellas: por un lado, fueron resaltados aquellos elementos que han dado testimonio de esta intención, tales como la oración por la unidad de la Iglesia, el testimonio común, la reflexión teológica en torno a temas como el bautismo, la eucaristía y el ministerio. Al mismo tiempo, fueron vistos con mayor claridad los difíciles obstáculos que aún permanecen en el camino. Juan Pablo II señaló en esa oportunidad que desde el principio de su ministerio como obispo de Roma, "insistĩ en que el compromiso de la Iglesia Católica con el movimiento ecuménico es irreversible."

Apenas un mes después, el Comité Central del Consejo Mundial de Iglesias, reunido también en Ginebra, eligí un nuevo secretario general, el pastor Emilio Castro. Nacido en Uru- guay, con una clara conciencia latinoamericana, Castro, desde hace mucho, viene acompañando y apoyando el desarrollo de nuevas formas de ser Iglesia en los diversos países de América Latina. Entre otras cosas fue responsable de la Conferencia Misionera Internacional que, en Melbourne (1980), afirmó la importancia del desafio que los pobres representan en todo el mundo ( $y$ no sólo en América Latina) para la Iglesia y para el cumplimiento de su vocación misionera. En la conferencia de prensa después de su elección, Castro señaló con respecto a la teología de la liberación que muchos de los té́logos de liberación eran sus amigos y que no sólo respetaba sus ideas, sino que también apreciaba el testimonio de su fe.

El documento de la Sagrada Congregación para la Doctrina de la Fe del Vaticano, suscrito por el Cardenal Ratzinger y por Monsehor Bovone, prefecto y secretario del organismo respectivamente, fue aprobado por Juan Pablo II el día 6 de agosto último. Bajo el título "Instrucción sobre algunos aspectos de la Teología de la Li- 
beración," el documento tiene la finalidad de "atraer la atención de los pastores, de los teólogos y de todos los fieles, sobre las desviaciones y los riesgos de desviación, ruinosos para la fe y para la vida cristiana, que implican ciertas formas de teología de la li. beración que recurren, de modo insuficientemente critico, a conceptos tomados de diversas corrientes del pensamiento maxista."

La teología de la liberación no se restringe al ámbito católico exclusivamente. Hay evangélicos tanto en América Latina como en Africa y en Asia, que también participan de esta corriente. Ella goza también de simpatias en circulos de las Iglesias ortodoxas. La advertencia de la instrucción presenta, consecuentemente, un problema ecuménico. Es a partir de la perspectiva del movimiento que procura crear condiciones para que las Iglesias y los cristianos marchen rumbo a la unidad, que exponemos a continuación algunas reflexiones sobre el alcance del documento.

\section{Una cuestión fundamental}

En 1980 el Consejo Mundial de Iglesias (CMI) definió su posición convocando a sus Iglesias miembros a ejercer una solidaridad activa con los pobres. En mayo de ese año, en la conferencia del Melbourne, se recomendó a las Iglesias que "llegasen a ser Iglesias solidaridas con las luchas de los pobres." Después de haber reconocido que en la Biblia la pobreza es una realidad que viene con la privación, la opresión y la aflicción, también recomendö "unir fuerzas en la lucha contra los poderes que explotan y empobrecen." Esa perspectiva permite comprender que la situación de los pobres deriva de conflictos, de contradicciones sociales. Dichos de modo más claro: de una lucha de cla. ses.

Esa posición fue ratificada cuan. do el comité central del CMI se reunió en agosto de 1980. Alli se puso a consideración un informe de la comisión para la participación de las Iglesias en el desarrollo cuyo título es "Rumbo a una Iglesia solidaria con los pobres." El comité central aprobó y recomendó la difusión del informe entre las Iglesias miembros para su estudio y reflexión. En forma aún más contundente que en la conferencia de Melbourne, en el informe se indica que la situación de los pobres constituye un caso de injusticia flagrante, cuyas causas son determinadas con la ayuda de las ciencias sociales. El documento contiene conceptos que tam. bién son empleados en el análisis marxista. No obstante nadie puede decir que ese texto (como tampoco el de Melbourne) puede adulterar la fe de los pobres y, menos aún, "traicionar su causa" (Instrucción, Introducción, pág. 4).

Varios años de sólido estudio precedieron la elaboración final de esos trabajos. Para su realización, fueron consultados hombres y mujeres de varias partes del mundo, incluyendo creyentes que viven en el mundo socialista. Cuando la Introducción del documento alerta sobre las desviaciones de ciertas formas de teología de la liberación (que, junto con otras corrientes teológicas, ayudó a llevar adelante esa reflexión ecumé. nica), tal advertencia alcanza también a) CMl.

Para éste, lo que importa primeramente, no son las afirmaciones teologicas. Lo prioritario es atender y comprender cuáles son los caminos a 
través de los cuales las Iglesias experimentan la fuerza renovadora del Espiritu Santo. Para la fe cristiana de nuestro tiempo, el desarrollo de la Iglesia de los pobres es indudable. mente el proceso más claro de esa renovación. El CMI tomó conciencia de ese hecho y llamó la atención de sus miembros para que lo apoyasen. Una actitud muy diferente se evidencia en el documento de la Sagrada Congregación para la Doctrina de la $\mathrm{Fe}$. Así como el texto ecuménico es un llamado a la libertad, el documento del Vaticano es una expresión de autoridad y de control. Ciertamente, los pobres no necesitan de más inspecciones o censuras (por mãs simpáticamente paternalista que ellas puedan ser), más, sí, de aquella solidaridad que se reclamaba a las Iglesias.

Aqui es donde radica la gran diferencia entre el documento de la Santa Sede y los del Consejo Ecuménico. En éstos los pobres son respetados: por más oprimidos o explotados que puedan ser, por más carentes de educación (formal académica) que se presenten, son personas maduras que tienen derechos. Entre ellos, el de dedicir por su propia cuenta, sin tutelas. Podríamos decir la misma cosa de otra manera: los documentos del CMI parten de los pobres y tienen en cuenta las luchas que ellos llevan adelante por su liberación. En cambio, la Instrucciōn, habla sobre liberación, sin tomar en cuenta que son los pobres los que más la necesitan. Parecería que estos no son capaces de poder llegar a través de la historia a dar testimonio de la libertad a que son convocados (como todos los seres humanos) por el Espíritu Santo.

\section{La libertad de los teólogos}

A fines de febrero de 1980 , en vispera del Congreso Internacional Ecuménico de Teología, que se realizó en Sao Paulo, el comité ejecutivo del CMI, reunido cerca de Estrasburgo (Francia), dio a conocer una declara. ción defendiendo la libertad del teólogo para investigar y desarrollar nuevos métodos de trabajo ante los desafíos que las cambiantes condiciones históricas colocan a la fe de la Iglesia. Habia transcurrido un lapso de apenas poco más de dos meses desde que Hans Kung, el profesor de teología suizo que enseña en la Universidad de Tubinga, fuera alcanzado por la prohibición de continuar enseñando en la facultad de teología de aquel centro académico. Para las autoridades católicas romanas, aquellas medidas de la institución ecuménica representaba una injerencia del consejo en asuntos internos de la Iglesia católica. El secretario general del CMl, el pastor Philip Potter, se encargó de señalar que toda acción que limita o intenta cortar la libertad de aquellos que recibieron del Espíritu Santo el don de explicitar el contenido de la doctrina de fe, no tiene un alcance limitado en el ámbito de la Igle. sia que toma tal decisión, en la medida que también afecta al resto de los teólogos.

La comunidad de fieles que creen en Jesucristo tiene la vocación de expresar la libertad para la cual Cristo nos liberó (Gal. 5,1). Para eso, es necesario que exista un espacio en el cual sea posible discutir aquellas posiciones que no coinciden entre sî. El conflicto en la vida de la Iglesia es algo ineludible: prueba de eso es el testimonio del libro los Hechos de los Apóstoles en el Nuevo Testamento. 
en el cual fueron registrados numero. sos choques entre los cristianos de la primera generación de creyentes. Enfrentamientos que, no obstante, no les disminuyeron la conciencia de estar unidos en Jesucristo. Esas contro. versias no se resolverán según los ar. gumentos de las autoridades, sino por medio de diálogos francos y sinceros.

La Instrucción parece haber sido redactada en un estilo que es opuesto al que caracteriza al movimiento ecuménico. En este, antes de finalizar un texto, se consulta a las Iglesias y personas que tienen algo que ver con el problema a que se refiere el documento. La participación de personas que provienen de medios muy diversos, el intercambio de ideas, expe- riencias y posiciones diferentes, lleva a elaborar documentos que reflejan esa pluralidad. Por eso mismo, llama la atención que un texto de tanta importancia haya sido elaborado sin consultar a las autoridades episcopa. les o teólogos que se definen a favor de la línea de la teología de la libera. ción, atacada por ese texto. Ese pro. cedimiento, lamentablemente, no puede ser considerado ecuménico.

Contrasta con la experiencia de la iglesia que toma vida y se nutre del movimiento del Espíritu Santo entre los pobres. En ésta hay participación, discusión abierta y fraternidad. Elementos propicios para poder des. arrollar con vitalidad y creatividad la investigación teológica. 